\title{
Significantly enhanced lung metastasis and reduced organ NK cell functions in diet- induced obese rats
}

\author{
J. Spielmann ${ }^{*}$ DD, J. Hanke², D. Knauf ${ }^{1}$, S. Ben-Eliyahu ${ }^{3}$, R. Jacobs ${ }^{4}$, G. I. Stangl ${ }^{5}$, I. Bähr ${ }^{1}$ and H. Kielstein ${ }^{1}$
}

\begin{abstract}
Background: Obesity was identified as a major risk factor for malignant diseases, but underlying mechanisms remain unclear. Natural killer (NK) cells, a pivotal aspect of innate immunity, are capable of identifying and killing virally infected and tumor cells. Previous studies have shown altered NK cell functions in obesity, and the current study aimed to investigate the relationship between altered NK cell functions and increased cancer risk in obesity.

Methods: To induce obesity male F344-rats received a high-fat diet (34\% fat) or a control diet (4\% fat). Thereafter, syngeneic mammary adenocarcinoma cells (MADB106) or a vehicle were intravenously (i.v.) injected. 15 min after injection, half of each group of rats were killed, lungs removed and immunohistochemically stained. Numbers of NK cells, MADB106 cells and NK cell-tumor cell interactions were quantified. Twenty-one days after tumor-cell injection the other half group of rats was killed and lung metastases were counted and relative mRNA concentrations of different NK cell receptors were determined.

Results: After short-term MADB106-challenge, DIO fed animals showed significantly decreased NK cell numbers in the blood and NK cell-tumor cell interactions in the lung as compared to their control littermates. Twenty-one days after MADB106 injection, the lungs of the DIO fed rats showed significantly more lung metastases compared to control animals, accompanied by reduced relative mRNA concentrations of the activating NK cell receptor NKG2D.

Conclusions: We conclude that induction of obesity in F344-rats leads to reduced lung NK cell function against tumor cells and results in significantly enhanced lung metastasis as compared to lean animals. It can be hypothesized that obesity-induced altered NK cell functions play an important role in cancer growth and metastasis.
\end{abstract}

Keywords: Natural killer cells, Obesity, High-fat diet, Diet-induced obesity, Cancer, NKG2D, Tumor cells

\section{Background}

Obesity is a worldwide problem, climaxing in the death of 2.8 million people every year [1]. Data of the Global Health Observatory show that in 2014 around 39\% of adults aged 18 and over were overweight and 13\% were obese [2]. Beside the risk of contracting coronary heart diseases, ischemic stroke, and type 2 diabetes mellitus, common cancers like postmenopausal breast, colon, kidney, esophagus, gallbladder, pancreas and skin cancer [3] are also known to be related to obesity. The underlying biological mechanisms still remain unclear, but there are

\footnotetext{
* Correspondence: Julia.Spielmann@uk-halle.de

${ }^{1}$ Department of Anatomy and Cell Biology, Martin Luther University Halle-Wittenberg, Faculty of Medicine, Grosse Steinstrasse 52, 06108 Halle (Saale), Germany

Full list of author information is available at the end of the article
}

several studies focusing on the link between obesity and cancer. Besides reduced insulin resistance [4], physical activity [5] and sex hormones [6], also the influence of obesity on immune functions is discussed [7]. Previous studies could show a central role of the adipocytokine leptin on the innate immune system [8-11]. Specifically natural killer (NK) cells seem to be functionally altered by obesity-induced high elevated leptin levels [11-13]. Interestingly, Wrann et al. [12] could show that long-term leptin stimulation significantly impairs NK cell functions such as cytotoxic lysis of tumor cells, interferon $\gamma$ (IFN $\gamma$ ) secretion, and cell proliferation. NK cells represent 10 to $15 \%$ of peripheral lymphocytes and are an essential part of the innate immune system. They play an important role in identifying and killing virally infected and tumor cells 
without prior sensitization and restriction by major histocompatibility (MHC) antigens [14]. NK cells detect their target cells by surface activating and inhibitory receptors and thereby regulate their activity [15]. After detection, NK cells induce apoptosis of target cells by exocytosis of granzymes and perforin and affect the functions of other immune cells by the release of cytokines, such as IFNY and tumor necrosis factor $\alpha$ (TNF $\alpha)$ to regulate immune responses [16].

A prospective study by Imai et al. showed that impaired functions of NK cells are associated with an increased incidence for cancer [17]. Additionally, obese patients who lost body weight by bariatric surgery or by exercise training and nutrition courses could reverse their impaired NK cell activity and NK cell-mediated cytokine synthesis $[7,18]$. This indicates that there might be a close interaction between impaired NK cell functions in obese individuals and the increased risk for cancer in obesity. Interestingly, there are only a few studies investigating the link of obesity, NK cells and malignant tumor development $[19,20]$.

Thus, the aim of the present study was to investigate the relationship between altered NK cell functions and increased cancer growth in obesity. F344-rats were fed a high-fat diet to induce obesity. Syngeneic mammary adenocarcinoma cells (MADB106) were i.v. injected to diet-induced obese and normal weight F344-rats to induce lung metastasis. NK cell functions were investigated at two different time points after inoculation of tumor cells. To investigate NK cell functions at an early time point, NK cell-tumor cell interactions and the expression of splenic NK cell receptors were determined $15 \mathrm{~min}$ after tumor cell challenge. Furthermore, numbers of lung metastases were determined at a late time point.

\section{Methods}

\section{Animals and experimental set-up}

Male Fischer F344-rats (6-week-old; $n=64$ ) were purchased from Charles River GmbH (Sulzfeld, Germany) and kept under controlled conditions at $23 \pm 2{ }^{\circ} \mathrm{C}$ and $55 \pm 5 \%$ relative humidity. Rats were maintained on a 12:12 h light dark cycle with lights on from 6 am to $6 \mathrm{pm}$. Rodent chow and water were available ad libitum. Half of the group $(n=32)$ was randomly selected to receive a high-fat diet (diet-induced obesity: DIO; $29 \%$ carbohydrate, $21 \%$ crude protein, $35 \%$ crude fat and $5.2 \mathrm{kcal} / \mathrm{g}$ metabolizable energy; C1090-60 Altromin, Lage, Germany) for 6 (short-term tumor challenge) or 10 weeks (long-term tumor challenge) to induce obesity. Control animals $(n=32)$ received the corresponding control diet (58\% carbohydrate, $21 \%$ crude protein, $4 \%$ crude fat and $3.5 \mathrm{kcal} / \mathrm{g}$ metabolizable energy; C109010, Altromin). Animals were weighed and handled by the scientists weekly. All research and animal care procedures were approved by the local Animal Care Committee of the "Landesverwaltungsamt Halle" (reference number 42502-2-1116MLU).

After feeding the high-fat diet, DIO animals started the experiments with a significant higher body weight as compared to their age-matched lean littermates.

Subsequently animals were i.v. inoculated with either $1 \times 10^{6}$ cells of an adenocarcinoma syngeneic tumor (MADB106) dissolved in $1 \mathrm{ml}$ isotonic saline or only $1 \mathrm{ml}$ of isotonic saline $(\mathrm{NaCl})$ via the tail vein.

Subsequently half of the animals were killed at an early time point, $15 \mathrm{~min}$ after tumor cell challenge (short-term experiment). The other half of the group of rats was admitted to develop lung metastases over a period of 21 days and therefore represent the late time point (long-term experiment). Rats of the long-term experiment received the diet according to their group (control or DIO) for the 21 days of lung metastases development until the end of the experiment.

\section{Culture and CFSE labeling of MADB106 tumor cells}

Cell culture and CFSE (fluorescein derivate 5- (and 6-) carboxyfluorescein diacetate succinimidyl ester)-labeling of cells were conducted as described elsewhere [21]. In brief, the MADB106 mammary adenocarcinoma syngenic tumor is a selected variant cell line obtained from a pulmonary metastasis produced by the intravenous injection of the 9-10 dimethyl-1-2-benzanthracene-induced MADB106 parental adenocarcinoma in F344-rats. Injecting $1 \times 10^{6}$ MADB106-cells via the tail vein of animals leads to pulmonary metastasis after 21 days. For in situ quantification $15 \mathrm{~min}$ after injection, tumor cells were vitally dye stained using CFSE (Cell Trace CFSE Cell Proliferation Kit, Molecular Probes, Eugene, USA) before injection [22].

\section{Blood and organ sampling}

Rats were killed under general isoflurane anesthesia either after 15 min (short-term tumor challenge; short-term experiment) or 21 days (long-term tumor challenge; longterm experiment) by puncture of the abdominal aorta. Blood was withdrawn and spleen and liver were removed. Organs were immediately frozen in liquid nitrogen and stored at $-80^{\circ} \mathrm{C}$ for RNA isolation and lipid analysis. Heparinized blood samples were stored on crushed ice. Subsequently, erythrocytes in the blood were destroyed by a lysis buffer (155 mM NH4Cl, $10 \mathrm{mM} \mathrm{KHCO3}$ and 0.01\% EDTA) to obtain leukocytes for following cytometric analysis.

\section{Lung preparation}

Lungs were processed as described by von Hörsten et al. [22]. Briefly, a cannula was inserted into the trachea in situ. Lungs and the heart were dissected from the chest and rinsed with $10 \mathrm{ml} 0.9 \% \mathrm{NaCl}$. Afterwards, lungs 
were transfused with $8 \mathrm{ml}$ of O.C.T. embedding medium (Sakura, Tokyo, Japan; diluted $1 / 5$ in PBS) for shortterm experiment or with Bouin's fixative (Sigma-Aldrich, Taufkirchen, Germany) for long-term experiment. Complete lungs were dissected at the hilum from the pulmonary trunk of the heart, frozen in liquid nitrogen and stored at $-80{ }^{\circ} \mathrm{C}$ for consecutive immunohistochemically staining for the short term experiment or immediately immersion fixed in Bouin's fixative for $24 \mathrm{~h}$ for long-term experiment.

\section{Immunohistochemically analysis of the lungs (short-term experiment)}

Frozen tissue samples of the right lobe were immersed in O.C.T. embedding medium and $5 \mu \mathrm{m}$ thick sections were cut and placed on glass slides. Every 15th section was selected with a random start, yielding 15-21 sections per animal. Selected sections were mounted on coated glass slides (Starfrost, Knittel, Braunschweig, Germany) and air dried.

Immunostaining of NK cells and CFSE-labeled MADB106 tumor cells was performed using monoclonal antibodies (mAbs) directed against the NK-RP1 receptor (CD 161 rat/ clone 10/78, BioRad AbD Serotec, Puchheim, Germany) on the NK cell surface and the intracellular CFSE antigen (anti-Fluorescein from mouse IgG1 clone B13-DE1, Roche Applied Science, Mannheim, Germany), respectively. Thereafter, APAAP (alkalinephosphatase-anti-alkaline-phosphatase-complex) staining was performed. Sections were fixed in acetone for $10 \mathrm{~min}$ and washed with TBS-Tween $(0.05 \%$ Tween 20 , Serva, Heidelberg, Germany) followed by the incubation with the primary anti-CFSE-mAb overnight at room temperature in humid chambers. Sections were washed with TBS-Tween followed by incubation for $30 \mathrm{~min}$ with the bridging antibody (Dako Z 0259, 1/50, rabbit anti-mouse, Dako, Hamburg, Germany) diluted in 5\% rat serum. After another rinse the APAAP complex (100 ml Dako D 0651, 1/50, mouse; in TBS-Tween) was added and the sections incubated for $30 \mathrm{~min}$ at room temperature. The incubations with bridging antibody and the addition of the APAAP complex were repeated once for $15 \mathrm{~min}$ followed by addition of the substrate Fast Blue (Sigma-Aldrich). Next the incubation with the primary antibody against CD161 was performed for $1 \mathrm{~h}$ followed by an identical secondary staining procedure except that Fast Red (Sigma) was used as substrate. Finally, sections were counterstained with hematoxylin and covered with glycergel mounting medium (Dako). The immunohistological investigations were carried out strictly under blind conditions. For counting of NK cells and NK cell-tumor cell contacts an area of $40 \mathrm{~mm}^{2}$ was evaluated by using the Software Image J software (US National Institutes of Health, Bethesda, MD, USA).
Visualization of lung metastasis (long-term experiment) Due to the fixation of lungs in Bouin's solution 21 days after inoculation of the MADB106 cells, subpleural lung surface metastases were identified by a light, white appearance. Surface metastases are $1-8 \mathrm{~mm}^{3}$, mushroomshaped, distinctly separated, and raised above the lung surface. All visible surface metastases were quantified by masked counting.

\section{Cytometric analysis}

FACS (Fluorescence Activated Cell Sorting) analysis was performed using the following mouse anti-rat mAbs: CD3 conjugated with allophycocyanin ( $\mathrm{T}$ cell receptor/CD3 $\mathrm{APC}$ ), and CD161a conjugated with phycoerythrin (NK cells/NKRP1A ${ }^{+} / \mathrm{CD} 161 \mathrm{a}^{\text {bright }} \mathrm{PE}, \mathrm{BD}$ Biosciences, San Diego, USA). Protected from light, cells were incubated for $30 \mathrm{~min}$ at $4{ }^{\circ} \mathrm{C}$. Thereafter, PBMCs were washed twice with washing buffer (PBS supplemented with 1\% BSA and 0.1\% sodium azide), resuspended in measuring buffer (PBS supplemented with $0.1 \%$ BSA and $0.1 \%$ sodium azide) and samples were analyzed by flow cytometry using LSR Fortessa with BD FACSDiva Flow Cytometry Software Version 6.2 (BD Biosciences, San Diego, USA; Fig. 1). NK cells are represented by the $\mathrm{CD} 161 \mathrm{a}^{\text {bright }} / \mathrm{CD}^{-}$population.

\section{Lipid analysis}

Lipids were extracted from liver with a mixture of nhexane and isopropanol $(3: 2, v / v)$ as already described [23]. For determination of the concentrations of cholesterol and triacylglycerols (TAG) in the liver, aliquots of the lipid extracts were dried and the lipids dissolved using Triton X-100 (Sigma-Aldrich) [24]. Concentrations

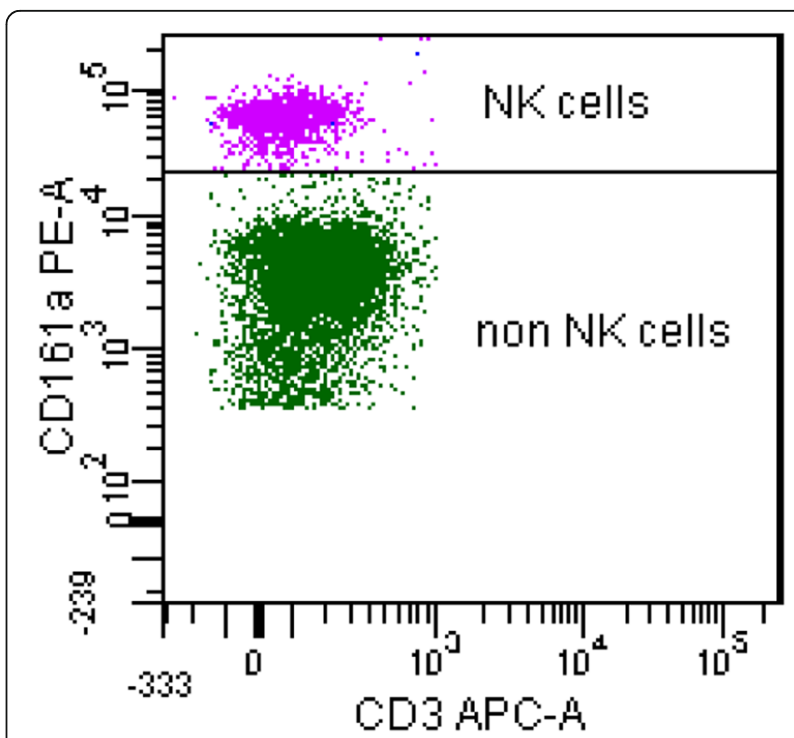

Fig. 1 Representative scatter-plot of flow cytometry analysis. NK cells are represented by cells with CD161abright and CD3- expression and denoted with NK cells 
of cholesterol and TAG in liver were determined using an enzymatic reagent kit (Ecoline $\mathrm{S}_{+}$, DiaSys $\mathrm{GmbH}$, Holzheim, Germany).

\section{RT-PCR analysis}

Total RNA was isolated by Precellys 24 (Pequlab, Erlangen, Germany) from frozen spleen samples using TRIZOL $^{\mathrm{ma}}$ (Sigma Aldrich) according to the manufacture's protocol. cDNA synthesis was carried out as described by Koenig \& Eder [25]. The mRNA concentrations of genes were measured by realtime detection PCR (iQ5, BioRad, München, Germany) using SYBR ${ }^{\circ}$ Green MIX (BioRad) and the specific primers (KiCqStart $^{\text {th }}$ Primers, Sigma Aldrich, Hamburg, Germany, Additional file 1: Table S1) following the manufacture's protocol. For determination of mRNA concentration a threshold cycle $(\mathrm{Ct})$ was obtained from each amplification curve using the software Bio-Rad iQ5 (BioRad). Calculation of the relative mRNA concentration was made using the $\Delta \Delta \mathrm{Ct}$ method [26] with individual amplification efficiency for each primer, determined by a standard curve with different dilutions of primers. The housekeeping gene Cyp18 was used for normalization (Additional file 1: Table S1).

\section{Statistics}

Data analysis was performed using the Graph Pad Prism Software V5 (GraphPad, Inc., La Jolla, CA, USA). For one-way ANOVA Tukey-test and for two-way ANOVA Bonferroni-test with the main factors "diet" and "tumor" were used as post-hoc tests. Means were considered significantly different at $p \leq 0.05$. Results are presented as means \pm standard error of the mean (SEM).

* indicates significant differences of means $(p \leq 0.05)$ between all groups analyzed by one-way ANOVA.
\# indicates significant differences of means $(p \leq 0.05)$ between rats receiving $\mathrm{NaCl}$ compared to rats receiving MADB106 cells analyzed by two-way ANOVA.

$\mathbb{S}$ indicates significant differences between rats receiving control diet compared to DIO animals $(p \leq 0.05)$ analyzed by two-way ANOVA.

\section{Results}

Body weight and lipid concentrations in the liver of rats In both experiments rats fed a DIO diet gained significantly more weight compared to rats fed a control diet (Table 1). In the long-term experiment significant weight gain of DIO-fed animals even continued after MADB106 tumor- cell- injection (Table 1). The concentrations of TAG and cholesterol levels in the liver were significantly higher in animals fed the DIO diet compared to rats fed the control diet (Table 1).

\section{FACS analysis}

Fifteen minutes after MADB106 cell injection (shortterm experiment) DIO fed rats showed significant lower percentage of NK cells of PBMCs compared to rats fed a control diet (Fig. 2). Twenty-one days after the tumor cell challenge (long-term experiment) NK cell numbers of PBMCs was not different between the groups (Fig. 2).

Relative mRNA concentrations of activating and inhibiting NK cell receptors and cytokines expressed in the spleen In the short-term experiment (15 min - tumor cell challenge) rats receiving MADB106 tumor cells showed significantly higher relative mRNA concentrations of the inhibiting NK cell receptor Klra1/Ly49 (killer cell lectin-like receptor, subfamily $\mathrm{A}$, member 1 ) in spleen independently of the dietary regimen (Fig. 3). Relative mRNA concentrations of TNFSF10/TRAIL (tumor necrosis factor (ligand)

Table 1 Body weight, TAG and cholesterol levels in the liver of rats in short-term and long-term experiment

\begin{tabular}{|c|c|c|c|}
\hline & \multirow{2}{*}{$\frac{\text { Short-term experiment }}{\text { MADB106 injection }}$} & \multicolumn{2}{|c|}{ Long-term experiment } \\
\hline & & MADB106 injection & 21d after MADB106 injection \\
\hline \multicolumn{4}{|c|}{ Body weight in $g$} \\
\hline Control & $290 \pm 3$ & $329 \pm 4$ & $333 \pm 5$ \\
\hline $\mathrm{DIO}$ & $304 \pm 4^{*}$ & $348 \pm 7^{*}$ & $363 \pm 8^{*}$ \\
\hline \multicolumn{4}{|c|}{ TAG in the liver in $\mu \mathrm{mol} / \mathrm{g}$} \\
\hline Control & $38 \pm 8$ & & $38 \pm 4$ \\
\hline $\mathrm{DIO}$ & $90 \pm 15^{*}$ & & $65 \pm 9^{*}$ \\
\hline \multicolumn{4}{|c|}{ Cholesterol in the liver in $\mathrm{\mu mol} / \mathrm{g}$} \\
\hline Control & $6.7 \pm 0.7$ & & $7.1 \pm 0.3$ \\
\hline DIO & $11.0 \pm 1.6^{*}$ & & $9.3 \pm 0.8^{*}$ \\
\hline
\end{tabular}

Values are means \pm SEM, $n=16$ rats/group

TAG triacylglycerols

*Mean values were significantly different from rats fed the control diet: $p \leq 0.05$ 

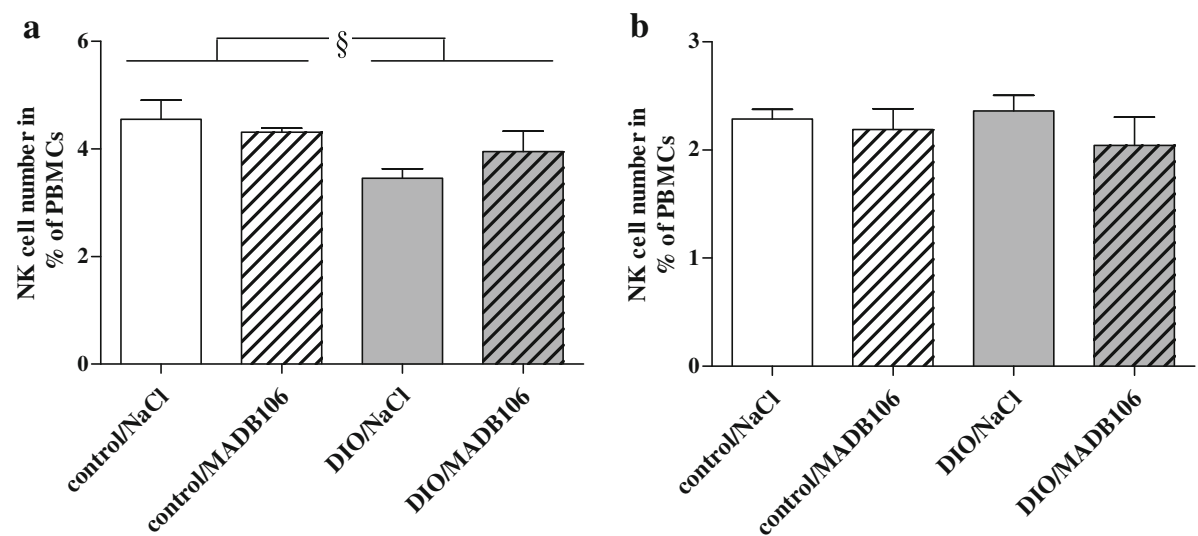

Fig. 2 Numbers of NK cells presented as \% of peripheral blood mononuclear cells (PBMCs). NK cell numbers are represented by the population with CD161 abright and $\mathrm{CD}^{-}$expression for (a) short-term experiment and (b) long term experiment and were determined by cytometry analysis after staining with the appropriate antibodies. Values represent means $\pm \mathrm{SEM}, n=8$ rats/group. $\S$ indicates significant differences of means between rats receiving control diet compared to DIO fed animals $(p \leq 0.05)$ analyzed by two-way ANOVA

superfamily, member 10/tumor necrosis factor related apoptosis inducing ligand) of DIO rats receiving MADB106 cells were significantly higher compared to those rats receiving $\mathrm{NaCl}$ (Fig. 3). Two-way ANOVA showed a significant influence of MADB106 tumor cell intervention and an interaction with diet on relative mRNA concentrations of TNFSF10/TRAIL in spleens of animals (Fig. 3). Rats did not differ in their relative mRNA concentrations of activating NK cell receptors NCR1/ NKp46 (natural cytotoxicity triggering receptor 1), NCR3/ NKp30 and Klrk1/NKG2D (killer cell lectin-like receptor $\mathrm{k} 1 /$ natural killer group 2D) and TNFo (Additional file 2: Table S2).

In the long-term experiment (21d - tumor cell challenge) DIO fed rats which developed lung metastases had significantly lower relative splenic mRNA concentrations of the activating NK cell receptor NCR1/NKp46 compared to the corresponding control rats receiving $\mathrm{NaCl}$ (Fig. 4). Additionally, two-way ANOVA also showed a DIO independent, significant inhibiting influence of tumor growth on relative mRNA concentrations of the NK cell activating receptor NCR1/NKp46 (Fig. 4). Relative mRNA concentrations of the activating NK cell receptor Klrk1/NKG2D was decreased in rats fed a DIO diet compared to control animals (Fig. 4). Relative mRNA concentrations of NCR3/NKp30, Klra1/Ly49, TNF $\alpha$ and TNFSF10/TRAIL in the spleens of rats did not differ between groups (Additional file 3: Table S3).

\section{Immunohistochemically quantification of NK cells,} MADB106 cells and NK cell-MADB106 cell interactions In the short-term experiment (15 min - tumor cell challenge) the tissue migration of both tumor cells and NK cells was investigated by immunohistochemistry, with
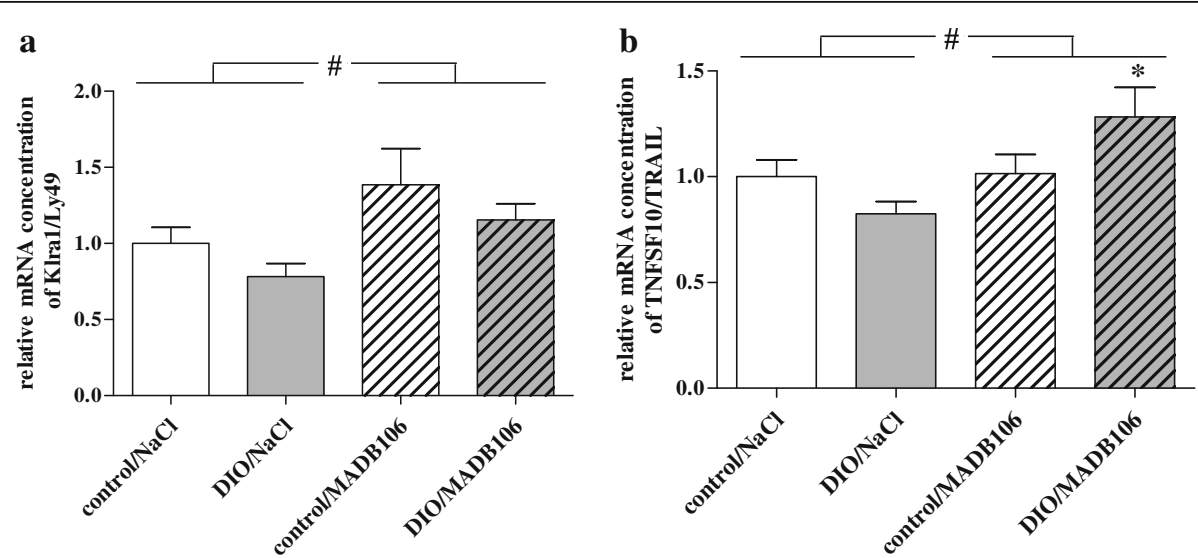

Fig. 3 Relative splenic mRNA concentrations of (a) Klra1/Ly49 and (b) TNFSF10/TRAIL in rats of short-term experiment. Values represent means \pm SEM, $n=8$ rats/group.* indicates significant differences of means ( $p \leq 0.05)$ compared to $\mathrm{DIO} / \mathrm{NaCl}$ analyzed by one-way ANOVA; \# indicates significant differences of means $(p \leq 0.05$ ) between rats receiving $\mathrm{NaCl}$ compared to rats receiving MADB106-cells analyzed by two-way ANOVA 

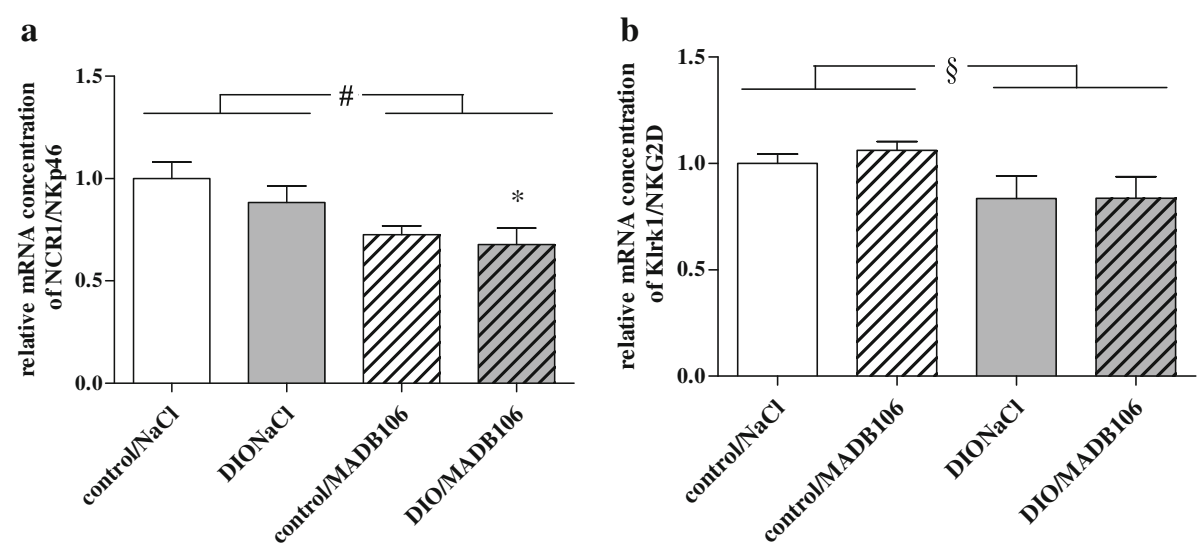

Fig. 4 Relative splenic mRNA concentrations of (a) NCR1/NKp46 and (b) Klrk1/NKG2D in rats of long-term experiment. Values represent means \pm SEM, $n=8$ rats/group; * indicates significant differences of means $(p \leq 0.05)$ compared to control/NaCl analyzed by one-way ANOVA; \# indicates significant differences of means $(p \leq 0.001$ ) between rats receiving NaCl compared to rats receiving MADB106 cells analyzed by two-way ANOVA; $\S$ indicates significant differences between rats receiving control diet compared to DIO animals $(p \leq 0.05)$ analyzed by two-way ANOVA

single- and double stained lung sections from animals of all experimental and control groups. DIO-fed rats showed significantly lower numbers of NK cells, MADB106 cells and NK cell-MADB106 cell interactions (Fig. 5).

\section{Quantification of lung metastases}

In order to quantify and compare the tumor growth between the experimental and control group, lung metastases were quantified 21 days after tumor challenge with MADB106 cells. Rats receiving DIO food developed significantly more lung metastases compared to their lean littermates (Fig. 6).

\section{Discussion}

Obesity is one major risk factor for certain types of cancer [27] and leads to a distinct impairment of various immune cell functions $[28,29]$. NK cells are a central component of the innate immune system, secreting different cytokines like IFN $\gamma$, interleukin-10 or TNF $\alpha$ to stimulate other immune cells, and are capable to directly destroy tumor cells $[16,30]$. NK cells express a wide range of activating and inhibitory surface receptors for recognizing and binding various targets [31]. It has been shown, that the NK cell functionality is significantly impaired in obese individuals $[12,32,33]$. Thus, the present study aimed to investigate effects of obesity on NK cell functions and tumor metastasis after short-term and long-term tumor cell challenge in rats. The first experiment was completed 15 min after tumor challenge and represents the early actions of NK cell defense against tumor cells. The second experiment was terminated 21 days after the tumor challenge and reproduces an advanced state of metastasis under the influence of obesity.

DIO fed rats showed significantly higher values in all three investigated obesity markers (body weight, liver cholesterol and TAG levels) in both experiments.

Results of the short-term tumor challenge showed significantly reduced NK cell numbers in the blood of DIO fed rats compared to the lean littermates. Reduced NK cell numbers could be one reason for the subsequent increased pulmonary metastasis of DIO fed rats, since NK cells play an important role in the early phase of metastasis and fight against tumor cells [34-36], including MADB106 [37]. In this study, 15 min after an intravenous inoculation of MADB106 tumor cells significantly less NK cells, tumor cells and NK cell-tumor cell contacts were found in the lungs of DIO fed rats, suggesting a mechanism that provokes the increased number of lung metastases evident 21 days later. Melemed et al. [38] identified marginating-pulmonary NK cells (MP-NK cells) in the lung capillaries, which showed an increased NK cytotoxicity compared to circulating NK cells and may have a special role in preventing invasion of tumor cells into the lung. In the case of the circulating MADB106 cells in our study, MP-NK cells seem to be influenced by diet-induced obesity, so that in DIO fed animals NK cell numbers in the lung are markedly reduced. In order to evaluate a possible modulation of the NK cell functionality by obesity, we determined the expression of different NK cell receptors. The activity of NK cells is regulated by a balance between activating and inhibiting receptors. Inhibiting NK cell receptors like KIRs in humans and Ly49 in rodents recognize MHC class I molecules and non-MHC ligands and eliminate cells lacking "self" MHC class I molecules according to the "missing self" hypothesis [39-41]. In contrast, 


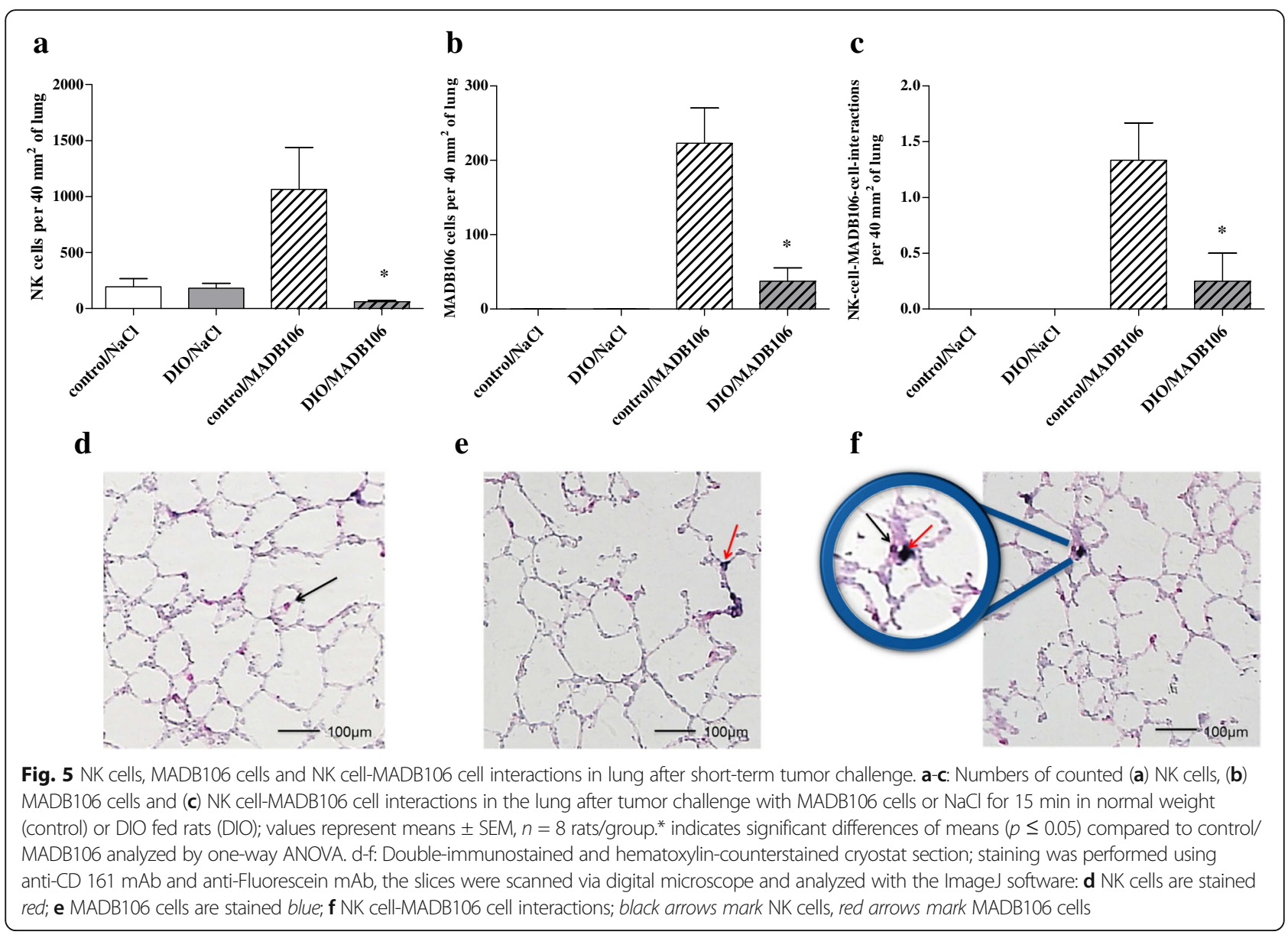

activating NK cell receptors, like NKp30, NKp46 and NKG2D, first bind to ligands expressed by tumor cells [42]. In all cases, NK cells exhibit their cytotoxic function after the recognition of target cells by secreting perforin and granzymes from intracellular granules to perforate the cell membrane and induce apoptosis of target cells [43]. Already after a short-term tumor cell challenge (15 $\mathrm{min})$ a significant increase of the expression of the inhibiting Ly49 receptor in the spleen of all tumor cell challenged animals was found, independently of the dietary regimen. It is known that cancer cells can escape immune recognition by upregulating inhibiting NK cell receptors and downregulating activating NK cell receptors [44]. This effect may also be one pathophysiological mechanism for the significantly reduced expression of the activating NK cell receptor NKp46 in all tumor animals 21 days after the tumor cell challenge in the present study. Concerning the late time point, results of the present study showed a significantly reduced expression of the activating NK cell receptor NKG2D in all DIO fed animals. Chung et al. [45] showed a significantly upregulated expression of NKG2D ligands in the adipose tissues of obese mice. In addition O'Rourke et al. [46] found significantly more NKG2D-expressing NK cells in human subcutaneous as well as visceral adipose tissues in obese individuals. Therefore it can be hypothesized that feeding an obesity inducing diet probably induces the upregulation of NKG2D ligands in adipose tissues, thereby recruiting NKG2D receptor expressing NK cells. As a consequence reduced numbers of NKG2D expressing NK cells can be found in the circulation or in other relevant tissues. This may lead to less NK cell-tumor cell contacts in the lung of DIO fed rats, finally resulting in a dramatically enhanced pulmonary metastasis compared to lean animals, as shown in the present study.

Moreover, we recently could show that incubation of the human NK cell line NK-92 with high levels of leptin led to significantly decreased NKG2D expression accompanied with a significant loss of NK cell cytotoxicity against colon cancer cells [20]. As it is known that leptin levels are markedly increased in obese subjects [33, 47, 48] this could be another possible mechanism for the impaired NK cell function and increased cancer risk observed during obesity.

Nevertheless, as the prevalence for obesity [2] and the incidence for obesity related cancers [49] constantly increase, further studies are required to verify these 


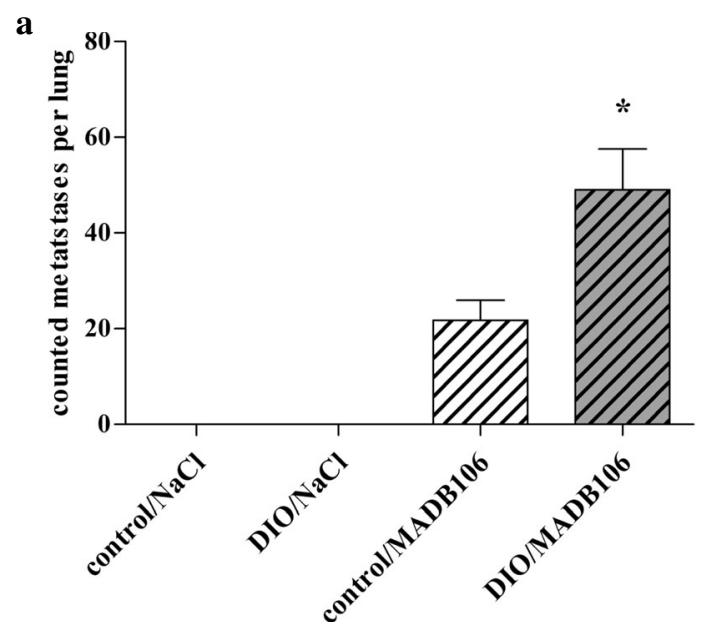

b
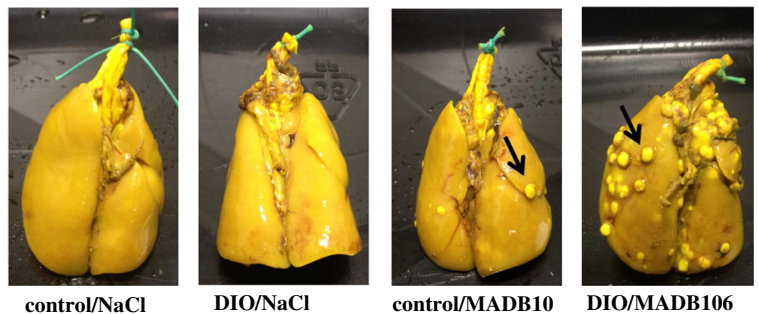

Fig. 6 Lung metastasis after long-term tumor challenge. Lungs were fixed in Bouin solution overnight, superficial metastasis appear white. a Numbers of superficial lung metastases after tumor challenge with MADB106-cells or NaCl for 21 days in normal weight (control) or DIO fed rats $(\mathrm{DIO}) ; n=8$ rats/group, ${ }^{*}$ indicates significant differences $(p \leq 0.05)$ of means analyzed by one-way ANOVA. $\mathbf{b}$ Representative photographs of the different lungs after fixation in Bouin solution; black arrows mark metastases

findings and elucidate new mechanisms underlying the influence of obesity on NK cells leading to the observed higher cancer outcome.

\section{Conclusions}

For the first time, a significantly increased lung metastasis in diet-induced obese rodents could be linked to reduced NK cell-tumor cell contacts and a decreased expression of the activating NK cell receptor NKG2D. As NK cells play a major role in tumor cell defense these data provide an important new aspect to elucidate mechanisms underlying obesity-related higher tumor risk. Future studies should further evaluate the molecular mechanisms of a reduced NK cell tissue migration and cytotoxicity in obese compared to normal weight individuals.

\section{Additional files}

Additional file 1: Table S1. Characteristics of the specific primers used for real-time RT-PCR analysis. (PDF $19 \mathrm{~kb}$ )

Additional file 2: Table S2. Relative mRNA concentrations of NK cell receptors and cytokines in spleen of rats in short-term experiment. (PDF 19 kb)

Additional file 3: Table S3. Relative mRNA concentrations of NK cell receptors and cytokines in spleen of rats in long-term experiment. (PDF 19 kb)

\section{Abbreviations}

APAAP: Alkaline-phosphatase-anti-alkaline-phosphatase-complex;

CFSE: Fluorescein derivate 5-(and 6-) carboxyfluorescein diacetate succinimidyl ester; Cyp 18: Cyclophilin A; DIO: Diet-induced obesity; IFNy: Interferon Y; KIra1: Killer cell lectin-like receptor, subfamily A, member 1; Klrk1: Killer cell lectin like receptor k1; MHC: Major histocompatibility complex; NCR1: Natural cytotoxicity triggering receptor 1; NCR3: Natural cytotoxicity triggering receptor 3; NK: Natural killer; NKG2D: Natural killer group 2D; SEM: Standard error of the mean; TAG: Triacylglycerols; TNFSF10: Tumor necrosis factor (ligand) superfamily, member 10; TNFa: Tumor necrosis factor a; TRAIL: Tumor necrosis factor related apoptosis inducing ligand

\section{Acknowledgements}

The authors thank Janine Jahn for her help in conducting the flow cytometric analyzes.

\section{Funding}

No funding was received.

\section{Availability of data and materials}

All data generated or analyzed during this study are included in this published article and its additional files.

\section{Authors' contributions}

$J \mathrm{~S}, \mathrm{IB}$ and HK planed the study. JS, JH and DK conducted the animal experiments and collected the blood and tissue samples. $\mathrm{JH}$ performed the immunohistochemical staining of the lungs and the interpreted the data together with JS. JH and JS conducted and analyzed the visualization of the lung metastasis and interpreted the data together. DK performed and interpreted the flow cytometric analyzes. JS analyzed and interpreted the Real-Time PCR data and conducted the cholesterol and triacylglycerol 
analyzes with the help of GIS. SBE and RJ provided the MADB106 cells and gave great support in culturing and staining the cells. JS, IB and HK were major contributors in writing the manuscript. All authors read and approved the final manuscript.

\section{Ethics approval and consent to participate}

All research and animal care procedures were approved by the local Animal Care Committee of the "Landesverwaltungsamt Halle" (reference number 42502-2-1116MLU).

\section{Consent for publication}

Not applicable.

\section{Competing interests}

The authors declare that they have no competing interests.

\section{Publisher's Note}

Springer Nature remains neutral with regard to jurisdictional claims in published maps and institutional affiliations.

\section{Author details}

${ }^{1}$ Department of Anatomy and Cell Biology, Martin Luther University Halle-Wittenberg, Faculty of Medicine, Grosse Steinstrasse 52, 06108 Halle (Saale), Germany. ${ }^{2}$ Department of Orthopaedics, Trauma and Reconstructive Surgery, Martin Luther University Halle-Wittenberg, Faculty of Medicine, Ernst-Grube Str. 40, 06097 Halle (Saale), Germany. ${ }^{3}$ Neuroimmunology Research Unit, The Sagol School of Neuroscience, The School of Psychological Sciences, Tel Aviv University, 69978 Tel Aviv, Israel. ${ }^{4}$ Department of Clinical Immunology and Rheumatology, Hannover Medical School, Carl-Neuberg-Str. 1, 30625 Hannover, Germany. ${ }^{5}$ Department of Human Nutrition, Martin Luther University Halle-Wittenberg,

Von-Danckelmann-Platz 2, 06120 Halle (Saale), Germany.

\section{Received: 19 September 2016 Accepted: 22 June 2017}

\section{Published online: 03 July 2017}

\section{References}

1. World Health Organisation. World Health statistics 2012

2. World Health Organisation. Obesity and Overweight: Factsheet No. 311. 2016.

3. Dobbins M, Decorby K, Choi BCK. The association between obesity and cancer risk: a meta-analysis of observational studies from 1985 to 2011. ISRN Prev Med. 2013:2013:680536. doi:10.5402/2013/680536

4. Tsugane $\mathrm{S}$, Inoue M. Insulin resistance and cancer: epidemiological evidence. Cancer Sci. 2010;101:1073-9. doi:10.1111/j.1349-7006.2010.01521.x.

5. McTiernan A. Mechanisms linking physical activity with cancer. Nat Rev Cancer. 2008;8:205-11. doi:10.1038/nrc2325.

6. Brown KA, Simpson ER. Obesity and breast cancer: progress to understanding the relationship. Cancer Res. 2010;70:4-7. doi:10.1158/00085472.CAN-09-2257.

7. Moulin CM, Rizzo LV, Halpern A. Effect of surgery-induced weight loss on immune function. Expert Rev Gastroenterol Hepatol. 2008;2:617-9. doi:10. 1586/17474124.2.5.617

8. La Cava A, Matarese G. The weight of leptin in immunity. Nat Rev Immunol. 2004:4:371-9. doi:10.1038/nri1350

9. Lord GM, Matarese G, Howard JK, Baker RJ, Bloom SR, Lechler RI. Leptin modulates the T-cell immune response and reverses starvation-induced immunosuppression. Nature. 1998;394:897-901. doi:10.1038/29795.

10. Tilg $H$, Moschen AR. Adipocytokines: mediators linking adipose tissue, inflammation and immunity. Nat Rev Immunol. 2006;6:772-83. doi:10. 1038/nri1937.

11. Nave H, Mueller G, Siegmund B, Jacobs R, Stroh T, Schueler U, et al. Resistance of Janus kinase-2 dependent leptin signaling in natural killer (NK) cells: a novel mechanism of NK cell dysfunction in diet-induced obesity. Endocrinology. 2008;149:3370-8. doi:10.1210/en.2007-1516.

12. Wrann CD, Laue T, Hübner L, Kuhlmann S, Jacobs R, Goudeva L, et al. Shortterm and long-term leptin exposure differentially affect human natural killer cell immune functions. Am J Physiol Endocrinol Metab. 2011;302:E108-16.

13. Tian Z, Sun R, Wei H, Gao B. Impaired natural killer (NK) cell activity in leptin receptor deficient mice: leptin as a critical regulator in NK cell development and activation. Biochem Biophys Res Commun. 2002;298:297-302.
14. Barão I, Ascensão JL. Human natural killer cells. Arch Immunol Ther Exp. 1998:46:213-29.

15. Vivier E, Tomasello E, Baratin M, Walzer T, Ugolini S. Functions of natural killer cells. Nat Immunol. 2008:9:503-10. doi:10.1038/ni1582.

16. Lanier LL. Up on the tightrope: natural killer cell activation and inhibition. Nat Immunol. 2008:9:495-502. doi:10.1038/ni1581.

17. Imai K, Matsuyama S, Miyake S, Suga K, Nakachi K. Natural cytotoxic activity of peripheral-blood lymphocytes and cancer incidence: an 11-year followup study of a general population. Lancet. 2000;356:1795-9. doi:10.1016/ S0140-6736(00)03231-1.

18. Jahn J, Spielau M, Brandsch C, Stangl Gl, Delank K-S, Bahr I, et al. Decreased NK cell functions in obesity can be reactivated by fat mass reduction. Obesity (Silver Spring). 2015;23:2233-41. doi:10.1002/oby.21229.

19. Lamas B, Nachat-Kappes R, Goncalves-Mendes N, Mishellany F, Rossary A, Vasson M-P, et al. Dietary fat without body weight gain increases in vivo MCF-7 human breast cancer cell growth and decreases natural killer cell cytotoxicity. Mol Carcinog. 2015:54:58-71. doi:10.1002/mc.22074.

20. Bahr I, Goritz V, Doberstein H, Hiller GGR, Rosenstock P, Jahn J, et al. Dietinduced obesity is associated with an impaired NK cell function and an increased Colon cancer incidence. J Nutr Metab. 2017;2017:4297025. doi:10. 1155/2017/4297025

21. Tschernig T, Boeke K, Steinhoff G, Wonigeit K, Pabst R, Westermann J. The lung as a source and a target organ for T- and B-lymphocytes. Am J Respir Cell Mol Biol. 1997;17:414-21. doi:10.1165/ajrcmb.17.4.2599.

22. Hörsten S von, Helfritz A, Kuhlmann S, Nave H, Tschernig T, Pabst R, et al. Stereological quantification of carboxyfluorescein-labeled rat lung metastasis: a new method for the assessment of natural killer cell activity and tumor adhesion in vivo and in situ. J Immunol Methods 2000;239:25-34.

23. Hara A, Radin NS. Lipid extraction of tissues with a low-toxicity solvent. Anal Biochem. 1978:90:420-6.

24. de Hoff JL, Davidson LM, Kritchevsky D. An enzymatic assay for determining free and total cholesterol in tissue. Clin Chem. 1978;24:433-5.

25. König B, Eder K. Differential action of 13-HPODE on PPARalpha downstream genes in rat Fao and human HepG2 hepatoma cell lines. J Nutr Biochem. 2006;17:410-8. doi:10.1016/j.jnutbio.2005.08.011.

26. Pfaffl MW. A new mathematical model for relative quantification in real-time RT-PCR. Nucleic Acids Res. 2001;29:e45.

27. Calle EE, Rodriguez C, Walker-Thurmond K, Thun MJ. Overweight, obesity, and mortality from cancer in a prospectively studied cohort of U.S. adults. N Engl J Med. 2003;348:1625-38. doi:10.1056/NEJMoa021423.

28. Andersen CJ, Murphy KE, Fernandez ML. Impact of obesity and metabolic syndrome on immunity. Adv Nutr. 2016;7:66-75. doi:10.3945/an.115.010207.

29. Chmelar J, Chung K-J, Chavakis T. The role of innate immune cells in obese adipose tissue inflammation and development of insulin resistance. Thromb Haemost. 2013;109:399-406. doi:10.1160/TH12-09-0703.

30. Vivier E, Raulet DH, Moretta A, Caligiuri MA, Zitvogel L, Lanier LL, et al. Innate or adaptive immunity? The example of natural killer cells. Science. 2011;331:44-9. doi:10.1126/science.1198687.

31. Koch J, Steinle A, Watzl C, Mandelboim O. Activating natural cytotoxicity receptors of natural killer cells in cancer and infection. Trends Immunol. 2013;34:182-91. doi:10.1016/j.it.2013.01.003.

32. Viel S, Besson L, Charrier E, Marcais A, Disse E, Bienvenu J, et al. Alteration of natural killer cell phenotype and function in obese individuals. Clin Immunol. 2016; doi:10.1016/j.clim.2016.01.007.

33. Laue T, Wrann CD, Hoffmann-Castendiek B, Pietsch D, Hubner L, Kielstein H. Altered NK cell function in obese healthy humans. BMC Obes. 2015;2:1. doi: 10.1186/s40608-014-0033-1.

34. Talmadge JE, Meyers KM, Prieur DJ, Starkey JR. Role of natural killer cells in tumor growth and metastasis: C57BL/6 normal and beige mice. J Natl Cancer Inst. 1980;65:929-35.

35. Gorelik E, Wiltrout RH, Okumura K, Habu S, Herberman RB. Role of NK cells in the control of metastatic spread and growth of tumor cells in mice. Int J Cancer. 1982;30:107-12.

36. Wu J, Lanier LL. Natural killer cells and cancer. Adv Cancer Res. 2003:90:127-56.

37. Ben-Eliyahu S, Page GG, Yirmiya R, Taylor AN. Acute alcohol intoxication suppresses natural killer cell activity and promotes tumor metastasis. Nat Med. 1996;2:457-60

38. Melamed R, Rosenne E, Benish M, Goldfarb Y, Levi B, Ben-Eliyahu S. The marginating-pulmonary immune compartment in rats: characteristics of continuous inflammation and activated NK cells. J Immunother. 2010:33:16-29. doi:10.1097/CJl.0b013e3181b0b146. 
39. Anfossi N, André P, Guia S, Falk CS, Roetynck S, Stewart CA, et al. Human NK cell education by inhibitory receptors for MHC class I. Immunity. 2006;25: 331-42. doi:10.1016/j.immuni.2006.06.013.

40. Kim S, Poursine-Laurent J, Truscott SM, Lybarger L, Song Y-J, Yang L, et al. Licensing of natural killer cells by host major histocompatibility complex class I molecules. Nature. 2005;436:709-13. doi:10.1038/nature03847.

41. Ljunggren $\mathrm{HG}$, Karre K. In search of the 'missing self': $M H C$ molecules and NK cell recognition. Immunol Today. 1990;11:237-44.

42. Inngjerdingen M, Kveberg L, Naper C, Vaage JT. Natural killer cell subsets in man and rodents. Tissue Antigens. 2011;78:81-8. doi:10.1111/j.1399-0039. 2011.01714.X.

43. Cullen SP, Martin SJ. Mechanisms of granule-dependent killing. Cell Death Differ. 2008;15:251-62. doi:10.1038/sj.cdd.4402244.

44. Chretien A-S, Le Roy A, Vey N, Prebet T, Blaise D, Fauriat C, et al. Cancerinduced alterations of NK-mediated target recognition: current and investigational pharmacological strategies aiming at restoring NK-mediated anti-tumor activity. Front Immunol. 2014;5:44. doi:10.3389/fimmu.2014.00122.

45. Chung J-J, Markiewicz MA, Polić B, Shaw AS, Vajreswari A. Role of NKG2D in obesity-induced adipose tissue inflammation and insulin resistance. PLoS One. 2014;9:e110108. doi:10.1371/journal.pone.0110108.

46. O'Rourke RW, Gaston GD, Meyer KA, White AE, Marks DL. Adipose tissue NK cells manifest an activated phenotype in human obesity. Metabolism. 2013; 62:1557-61. doi:10.1016/j.metabol.2013.07.011.

47. Smith AG, Sheridan PA, Harp JB, Beck MA. Diet-induced obese mice have increased mortality and altered immune responses when infected with influenza virus. J Nutr. 2007;137:1236-43.

48. O'Shea D, Cawood TJ, O'Farrelly C, Lynch L, Zimmer J. Natural killer cells in obesity: impaired function and increased susceptibility to the effects of cigarette smoke. PLoS One. 2010;5:e8660. doi:10.1371/journal.pone.0008660.

49. Polednak AP. Estimating the number of U.S. incident cancers attributable to obesity and the impact on temporal trends in incidence rates for obesity-related cancers. Cancer Detect Prev. 2008;32:190-9. doi:10.1016/j.cdp.2008.08.004

\section{Submit your next manuscript to BioMed Central and we will help you at every step:}

- We accept pre-submission inquiries

- Our selector tool helps you to find the most relevant journal

- We provide round the clock customer support

- Convenient online submission

- Thorough peer review

- Inclusion in PubMed and all major indexing services

- Maximum visibility for your research

Submit your manuscript at www.biomedcentral.com/submit

) Biomed Central 